International Journal of Agriculture, Environment and Bioresearch

Vol. 06, No. 02; 2021

ISSN: $2456-8643$

\title{
NEW SPECIES OF GENUS Gasteracantha (Araneae: Araneidae) IN MINDANAO, PHILIPPINES
}

\author{
Geonyzl L. Alviola ${ }^{123}$ Alma B. Mohagan ${ }^{2}$ and Michael Janicki ${ }^{3}$ \\ Davao Doctors College ${ }^{1}$, Central Mindanao University ${ }^{2}$ and iNaturalist.org ${ }^{3}$ \\ https://doi.org/10.35410/IJAEB.2021.5617
}

\begin{abstract}
A new species of Gasteracantha was reported from Mt. Kitanglad in Bukidnon and Salumay in Marilog District. This species was collected by handpicking method, within the boundaries of a montane forest. The collected sample was described and stored in a vial containing 95\% analytical ethyl alcohol. Then the described specimen was compared to a related species found in China. The new species was named as Gasteracantha mindanaoensis sp. nov.
\end{abstract}

Keywords: Gasteracantha, Gasteracantha mindanaoensis sp. nov., Kitanglad,

\section{INTRODUCTION}

Sundevall described the genus Gasteracantha with hard, thorny and colorful abdomen (Sundevall, 1833b). The name derived from two Greek words gaster (belly) and akantha (thorn or spine) (Bartlett, 2004). According to Global Biodiversity Information Facility (GBIF), the genus Gasteracantha had 7, 946 occurrences and 98 species recorded from 1700 to present. In occurrences, were categorized according to human observations $(59.1 \%)$, preserved specimens (39.1\%), material sample (1.3\%) and unknown (0.6\%) (GBIF, 2019). In Philippines, there were 153 recorded occurrences undescribed. The examined specimen was collected from Mt. Kitanglad and Salumay and compared to a related species discovered in China by Mi and Peng in 2013.

\section{METHODS}

Entry Protocol, permits and prior inform consents were secured from the different LGU (local government units) of Bukidnon and Salumay to acquire a gratuitous permit (GP) from the Department of Environment and Natural Resources (DENR). The specimen collected through active search and preserved in two ways. First $95 \%$ ethyl alcohol in a glass vial to maintain its color but the spider joints fixed and second in $70 \%$ ethyl alcohol for dissection because the joints were slightly movable. The epigynum was soaked with $\mathrm{NaOH}$ for a few minutes. The specimen was measured $(\mathrm{mm})$ and documented using a LCD stereomicroscope.

Abbreviations: AME- anterior median eyes, ALE- anterior lateral eyes, $\mathrm{PME}$ - posterior median eyes, PLE- posterior lateral eyes. 


\section{MATERIAL EXAMINED}

Samples were collected in Salumay, Marilog District, Davao City, Philippines (7²9' 18.84" N; $125^{\circ} 15^{\prime} 14.49^{\prime \prime}$ E) 1,291.44 masl and Mt. Kitanglad, Brgy. Intavas, Kaatuan, Bukidnon, Philippines ( $8^{\circ} 9^{\prime}$ 59.4432" N; $124^{\circ}$ 55' 57.8208" E), 1,300 masl. Collector: G.L. Alvoila and A. B. Mohagan. Confirmation: M. Janicke. Two female samples from Salumay and Intavas. Holotype female, resembled with the G. aureola was discovered from China (Mi and Peng, 2013). But it differs on the following morphological characteristics: The anterior carapace margin was procurved for G. mindanaoensis while straight margin for G. aureola.
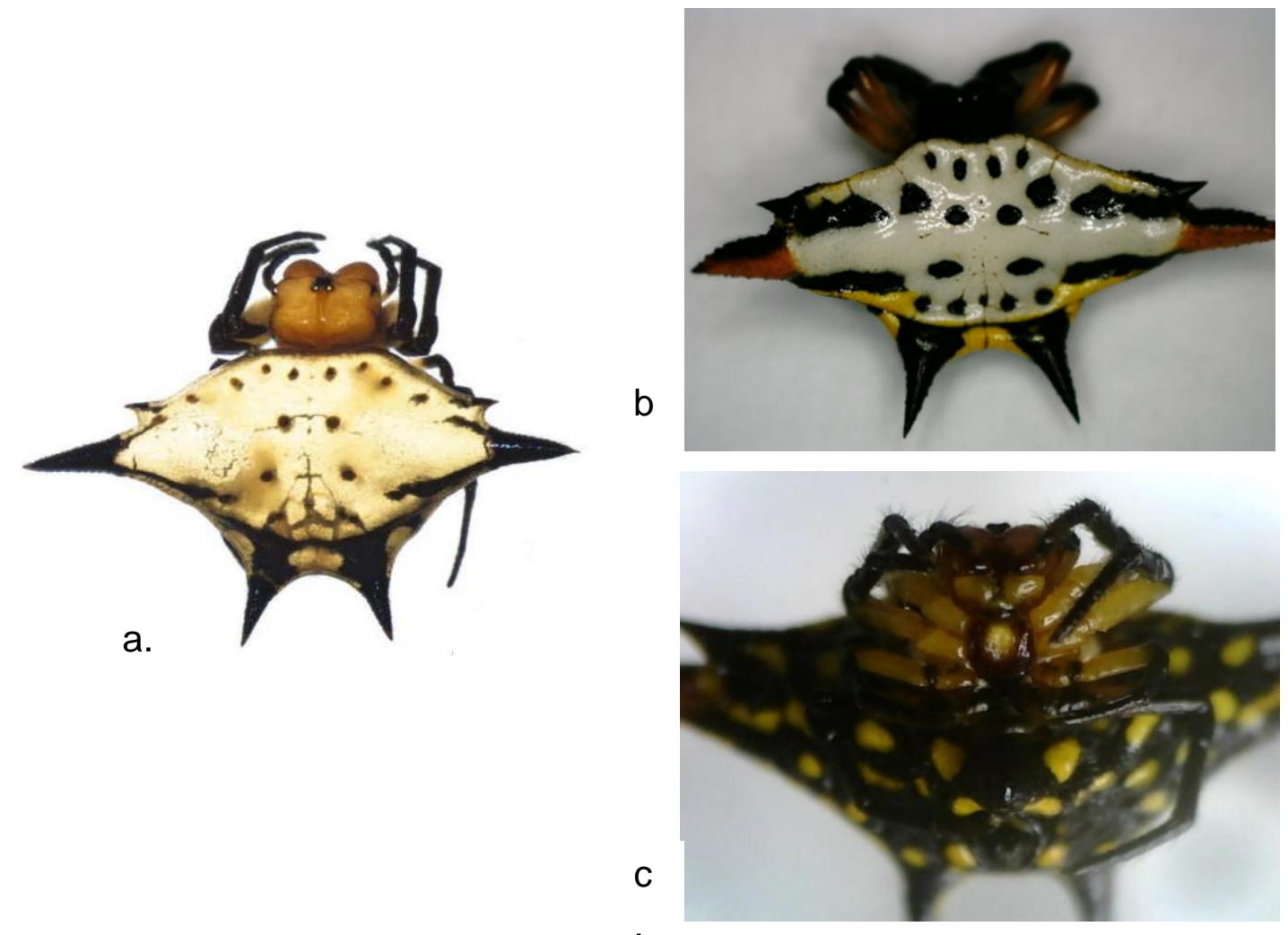

Figure 1. a) G. aureola (Mi \&Peng, 2013) and (b-c) dorsal and ventral view of G. mindanaoensis sp. nov. 
a



b.

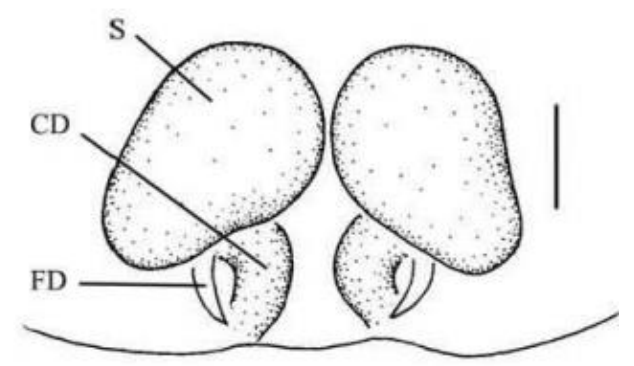

c

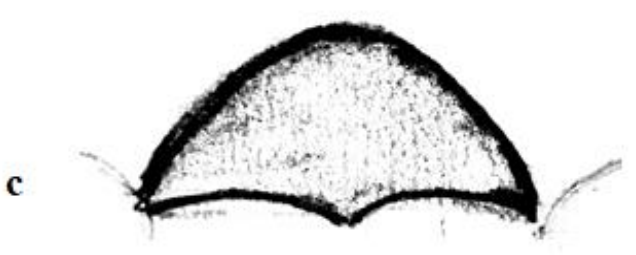

d

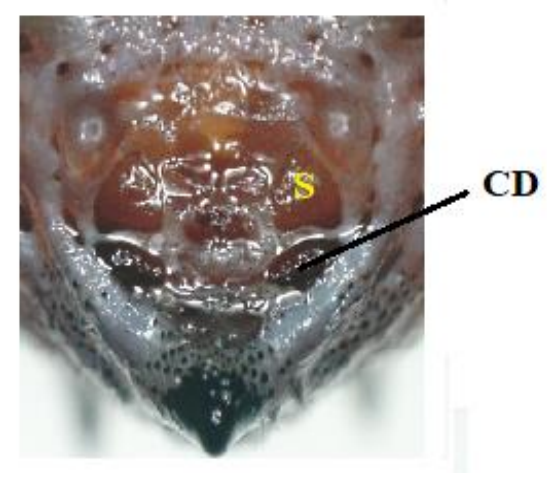

Figure 2. Epigynum: G. aureola (a. uncleared and b. cleared) (Mi and Peng 2013) and G. mindanaoensis (c. uncleared and d. cleared). S (spermathecae) and CD (copulatory duct).

Legs short, almost black from tibia to tarsus with yellowish femora to coxa. Opisthosoma was wider than long, the anterior and posterior spines were black and the medial lateral spines had black and red coloration on each margin. Like the G. aureola anterior spines weakest, while the median spines strongest (Figure 1b). Eye sizes and interdistances: ALE 0.10, PLE 0.12, AME 0.11, PME 0.14, AME-AME 0.12, PME-PME 0.13, PME-PLE 0.26, AME-ALE 0.29. Leg measurements: I 5.90, II 5.53, III 4.11, IV 6.31. Eyes were homogenous black. Epigyne with triangular scape, copulatory openings located posteriorly and spermathecae bell shape (Figure 1d).

Etymology: The specific name "mindanaoensis" comes from the main island of Philippines "Mindanao" where the spider was discovered.

Distribution: Mountains of central Mindanao like Bukidnon and Marilog District, Davao City. Ecological conservation status: Rare, least concern

Remarks: This spider was collected near the forest edge. The web was built at the lower canopy.

\section{Acknowledgements}

The researchers would like to thank the following: David J. Ringer from inaturalist.org, Steven Williams, for the suggestion in dissection. DENR, CMU, LGU of Mt. Kitanglad and Salumay. Almighty God for providing everything we need in the study. 
International Journal of Agriculture, Environment and Bioresearch

Vol. 06, No. 02; 2021

ISSN: $2456-8643$

\section{REFERENCES}

Bartlett, T. (2004, February 16). Genus Gasteracantha. Retrieve (2019, November 11), from bugguide.net/node/view/1982\#etymology.

Sundevall, C. J. (1833b). Conspectus Arachnidum. LondiniGothorum, pp. 1-39.

Mi, X. Q. \& Peng, X. J. (2013b). One new species and one new record species of the genus Gasteracantha (Araneae, Araneidae) from China. Acta Zootaxonomica Sinica 38: 795800 . 